Original Article

\title{
Epidemiology and psychological factors of whiplash associated disorders in Japanese population
}

\author{
Hiroyuki OKa, MD, $\mathrm{PhD}^{1)^{*}}$, Ko Matsudaira, MD, $\mathrm{PhD}^{1)}$, Tomoko Fuji, $\mathrm{MD}, \mathrm{PhD}^{1,2)}$, \\ Sakae Tanaka, MD, $\mathrm{PhD}^{3)}$, Tomoaki Kitagawa, $\mathrm{MD}, \mathrm{PhD}^{4}$ ) \\ 1) Department of Medical Research and Management for Musculoskeletal Pain, 22nd Century \\ Medical \& Research Center, Faculty of Medicine, The University of Tokyo: 7-3-1 Hongo, Bunkyo, \\ Tokyo 113-8655, Japan \\ 2) Japan Labour, Health and Welfare Organization, Kanto Rosai Hospital, Japan \\ 3) Department of Orthopaedic Surgery, The University of Tokyo, Japan \\ 4) Department of Orthopaedic Surgery, Teikyo University School of Medicine, Japan
}

\begin{abstract}
Purpose] This study was designed to examine the epidemiological background of Whiplash-associated disorders in Japanese adults and to investigate the psychological factors associated with prolonged treatment for Whiplash-associated disorders. [Subjects and Methods] An online survey was completed by 127,956 participants, of whom 4,164 had been involved in a traffic collision. A random sample of the collision participants $(\mathrm{n}=1,698)$ were provided with a secondary questionnaire. From the 974 (57.4\%) participants who returned the questionnaire, 183 cases (intractable neck pain treated over a period of 6 months) and 333 controls (minor neck pain treated within 3 months) were selected. Among the control group, the psychological factors associated with prolonged treatment for Whiplash-associated disorders were investigated. [Results] Among the 4,164 collision participants, 1,571 (37.7\%) had experienced Whiplash-associated disorders. The prevalence in the general population was $1.2 \%$ (1.3\% in male and $1.0 \%$ in female). Significant differences were observed between the cases and controls for all psychological factors, although both groups had similar distributions of age and gender. [Conclusion] Poor psychological factors were associated with prolonged treatment for whiplash-associated disorders in Japanese adults. These psychological factors should be considered during the treatment of whiplash-associated disorders.

Key words: Whiplash-associated disorders, Psychological factors, Prolonged treatment
\end{abstract}

(This article was submitted Apr. 11, 2017, and was accepted Jun. 2, 2017)

\section{INTRODUCTION}

Whiplash-associated disorders (WAD) are the most common injury associated with car collisions in Japan and many Western countries ${ }^{1,2)}$. However, there is no clear epidemiological data regarding the prevalence of WAD in Japanese adults. Although the prognosis of WAD is generally favorable, previous studies have found that up to $50 \%$ of the affected individuals are still symptomatic one year after the injury ${ }^{3)}$. In addition, there is evidence from previous studies that depression is associated with poor recovery from $\mathrm{WAD}^{4,5}$. However, the patient's poor psychological condition, such as depression and fear, actually refers to a hyperbolic negative perception of actual or anticipated pain ${ }^{6}$, and this perception can prolong WAD treatment. To our knowledge, the psychological factors in the Japanese population with WAD have not been studied, and are not clearly understood.

Therefore, this study aimed to evaluate the epidemiological background of WAD in Japanese adults. Furthermore, we

*Corresponding author. Hiroyuki Oka (E-mail: okah-tky@umin.ac.jp)

(C2017 The Society of Physical Therapy Science. Published by IPEC Inc.

(c) (1) $\odot$ This is an open-access article distributed under the terms of the Creative Commons Attribution Non-Commercial No Derivatives

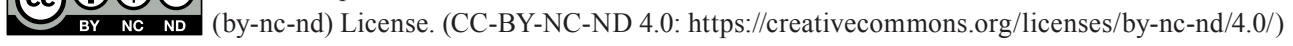


investigated the psychological factors associated with prolonged treatment for WAD, and reported the descriptive statistics for these factors.

\section{SUBJECTS AND METHODS}

Details of the study population have been described previously ${ }^{7}$. Briefly, we conducted an online survey to assess the prevalence of WAD in the general population. Participants were recruited through an internet research company. The initial survey was conducted online from July 1, 2012 through July 17, 2012. A total of 127,956 respondents completed items. This study was approved by the ethics review board of the Japan Labour Health and Welfare Organization.

The participants who had been in a traffic collision were considered relevant $(n=4,164)$. From this sample, 1,698 participants were randomly selected to participate in a secondary survey. Of the 974 (57.4\%) participants who returned the secondary questionnaire, we excluded 44 participants who were not wearing a seatbelt when the collision occurred, as these were likely to have sustained serious injuries. From the 930 remaining subjects, 183 were included in our intractable group (neck pain treated over a period of 6 months) and 333 were included in the control group (minor neck pain treated within 3 months). There was no article defined the period of the early recovery of WAD. Thus we clinically decided that the upper limit of early recovery is 3 months and set as a control group for intractable group.

The questionnaire evaluated socio-demographic data, age, gender, weight, height, education (not college, college, or other), driving status, and whether the participant had been in a traffic accident. If participants had been injured in a traffic collision, the car crash severity (mild, moderate, or severe), presence or absence of WAD, and length of unemployment (none, 1-3 days, 4-7 days, 1-4 weeks, $\geq 1$ month) were also evaluated in the initial survey. Body mass index (BMI; $\mathrm{kg} / \mathrm{m}^{2}$ ) was calculated using the self-reported weight and height; overweight was defined as BMI $\geq 25$.

We evaluated kinesiophobia using the Tampa Scale of Kinesiophobia (TSK), which is one of the most frequently employed measures for assessing fear. Each 17-item questionnaire is measured on a four-point Likert scale, and scores range from 17 (no fear) to 68 (strong fear of re-injury ${ }^{8)}$. The Japanese version of TSK has been linguistically validated ${ }^{9)}$. Pain catastrophizing was evaluated using the Pain Catastrophizing Scale (PCS $)^{10,11)}$, which is a 13-item self-reported tool that asks participants to reflect on past painful experiences and to indicate the degree to which they experience thoughts or feelings during pain. Scores are ranked on a 5-point scale, ranging from 0 (not at all) to 4 (always).

Depression was defined as a score of $\leq 52$ on the SF-36 Mental Health summary (SF-36 MH, version 1.2), as this score is the established cutoff value for Japanese adults ${ }^{12,13}$. Somatizing tendency was assessed using a subset of items from the Brief Symptom Inventory (BSI) ${ }^{14)}$; the Japanese version has been linguistically validated ${ }^{15}$. Seven somatic symptoms (faintness or dizziness, pain in the heart or chest, nausea or upset stomach, difficulty breathing, numbness or tingling in parts of the body, weakness in parts of the body, and hot or cold spells) were assessed on a 5-point scale, ranging from 0 (not at all) to 4 (extreme). A BSI score $\geq 2$ was considered indicative of somatization ${ }^{14,16)}$.

We also used the EuroQol-5 dimension (EQ-5D) questionnaire to evaluate general quality of life (QOL) ${ }^{17}$, 18). The fivedimensional health care classification evaluates the patient's status regarding morbidity, self-care, usual activities, pain/ discomfort, and anxiety/depression. Participants were asked to indicate their current health status by selecting the most appropriate of the three statements for each of the five QOL dimensions, where each statement represented an increasing degree of severity. These results were coded and converted into a score of utility, using a standard table of values.

Results were presented as frequencies and proportions (percentages), or as means and standard deviations (continuous variables). All statistical tests were performed using SPSS version 20.0 (SPSS Inc., Chicago, IL, USA). The $\chi^{2}$ test was used for nominal and ordinal data, and one-way analysis of variance was used for scaled data. Differences were considered statistically significant at a p-value of $<0.05$.

\section{RESULTS}

Demographic data for the respondents $(n=127,956)$ to the initial questionnaire are listed in Table 1. Of these respondents, $4,164(3.3 \%)$ had been injured in a traffic collision, and the characteristics of the collision and subsequent injury are listed in Table 2. Of the participants who had been in a collision, 1,571 (37.7\%) were diagnosed with WAD. The prevalence of WAD in the general population was $1.2 \%$ (1.3\% in male and $1.0 \%$ in female) (Table 3). Significant differences were observed between the intractable group and the control group regarding TSK, PCS (total and each component), SF36-MH, BSI, and EQ-5D (Table 4). No significant difference was detected between the groups regarding age or gender.

\section{DISCUSSION}

Little epidemiological information is available regarding WAD in Japan. In this study, 4,164 participants reported being injured in a traffic collision, of whom $37.7 \%$ were diagnosed with WAD; a similar prevalence of WAD was reported in a previous study ${ }^{2}$. The present study also clarified the age-gender distribution of WAD in the Japanese population. If our results are extrapolated to the Japanese population using the 2010 census data ${ }^{19}$ ), approximately 980,000 persons $(590,000$ male and 390,000 female) aged 20 years and older are affected by WAD. 
Table 1. Characteristics of the initial survey respondents $(\mathrm{n}=127,956)$

\begin{tabular}{lc}
\hline Age years, mean \pm SD & $47.7 \pm 10.8$ \\
Male, $\mathrm{n}(\%)$ & $81,387(63.6 \%)$ \\
Overweight $(\mathrm{BMI} \geq 25), \mathrm{n}(\%)$ & $30,556(23.9 \%)$ \\
Education level, n (\%) & \\
$\quad$ Not college & $73,747(57.6 \%)$ \\
$\quad$ College & $53,445(41.8 \%)$ \\
$\quad$ Other & $764(0.6 \%)$ \\
Driving status, n (\%) & \\
$\quad$ No license or occasional driver & $29,193(22.8 \%)$ \\
$\quad$ Normal driver & $95,377(74.5 \%)$ \\
$\quad$ Professional driver & $3,386(2.7 \%)$ \\
Traffic accident, n (\%) & \\
$\quad$ Collision & $4,164(3.3 \%)$ \\
Other & $6,155(4.8 \%)$ \\
$\quad$ None & $9,475(18.0 \%)$ \\
\hline
\end{tabular}

SD: standard deviation; BMI: body mass index

Table 3. Prevalence of whiplash-associated disorders according to age and gender $(n=127,956)$

\begin{tabular}{crcrrr}
\hline \multirow{2}{*}{$\begin{array}{c}\text { Age } \\
\text { (years) }\end{array}$} & \multicolumn{3}{c}{ N } & & \multicolumn{2}{c}{ Male } & Prevalence (\%) & & $\mathrm{N}$ & Prevalence (\%) \\
\cline { 2 - 3 } & 715 & 1.3 & & 973 & 0.7 \\
$25-29$ & 1,668 & 2.1 & & 2,428 & 1.2 \\
$30-34$ & 3,784 & 1.8 & & 4,633 & 1.0 \\
$35-39$ & 8,208 & 1.6 & & 7,849 & 0.9 \\
$40-44$ & 12,139 & 1.5 & & 8,945 & 1.0 \\
$45-49$ & 13,742 & 1.6 & & 7,503 & 1.1 \\
$50-54$ & 13,419 & 1.2 & & 6,051 & 1.0 \\
$55-59$ & 10,217 & 1.3 & & 3,897 & 0.9 \\
$60-65$ & 10,734 & 0.9 & & 2,972 & 0.9 \\
$65-69$ & 6,761 & 1.0 & 1,318 & 0.6 \\
Total & 81,387 & 1.3 & 46,569 & 1.0 \\
\hline
\end{tabular}

Table 2. Collision and injury related characteristics from the initial survey $(n=4,164)$

\begin{tabular}{lr}
\hline Car crash severity, n (\%) & \\
Minor & $956(23.0 \%)$ \\
Moderate & $1,387(33.3 \%)$ \\
Severe & $1,821(43.7 \%)$ \\
WAD, n (\%) & $1,571(37.7 \%)$ \\
Length of unemployment, n (\%) & \\
None & $2,838(68.2 \%)$ \\
1-3 days & $730(17.5 \%)$ \\
4-7 days & $152(3.7 \%)$ \\
$1-4$ weeks & $226(5.4 \%)$ \\
$\geq 1$ month & $218(5.2 \%)$ \\
\hline
\end{tabular}

WAD: whiplash-associated disorder
Table 4. The characteristics and psychological factors of whiplash-associated disorder patients

\begin{tabular}{lcc}
\hline & $\begin{array}{c}\text { Cases } \\
(\mathrm{n}=183)\end{array}$ & $\begin{array}{c}\text { Controls } \\
(\mathrm{n}=333)\end{array}$ \\
\hline Age & $44.8 \pm 10.3$ & $45.3 \pm 11.7$ \\
Gender, male/female & $124 / 59$ & $242 / 91$ \\
TSK & $44.0 \pm 9.1$ & $34.5 \pm 9.5^{*}$ \\
PCS & $32.7 \pm 10.6$ & $17.5 \pm 10.5^{*}$ \\
$\quad$ rumination & $14.8 \pm 4.1$ & $8.9 \pm 4.8^{*}$ \\
$\quad$ magnification & $6.9 \pm 3.0$ & $3.8 \pm 2.9^{*}$ \\
$\quad$ helplessness & $11.0 \pm 4.9$ & $4.9 \pm 4.1^{*}$ \\
SF-36 MH, n (\%) & & \\
$\quad \leq 52$ & $99(54.1 \%)$ & $116(34.8 \%) \dagger$ \\
$\quad>52$ & $84(45.9 \%)$ & $217(65.2 \%)$ \\
BSI, n (\%) & $157(85.8 \%)$ & $167(50.2 \%) \dagger$ \\
$\quad \geq 2$ & $11(6.0 \%)$ & $38(11.4 \%)$ \\
$\quad 1$ & $15(8.2 \%)$ & $128(38.4 \%)$ \\
$\quad 0$ & $0.674 \pm 0.178$ & $0.923 \pm 0.129^{*}$ \\
\hline EQ-5D, mean (SD) &
\end{tabular}

TSK: Tampa Scale for Kinesiophobia; PSC: Pain Catastrophizing Scale; SF-36 MH: SF-36 Mental Health summary (version 1.2); BSI: Brief Symptom Inventory; EQ-5D: EuroQol-5 dimension questionnaire

Mean $\pm \mathrm{SD}$, *Statistical difference as determined by oneway analysis of variance $(\mathrm{p}<0.01)$; $\uparrow$ Statistical difference as determined by $\chi^{2}$ test $(\mathrm{p}<0.01)$

Furthermore, we also investigated the psychological factors associated with prolonged treatment for WAD in Japanese adults. Using randomly selected participants who had been in a collision, we formed a sub-cohort of symptomatic WAD patients to evaluate their psychological factors. Intractable and control groups were evaluated for representative psychological factors and health-related QOL, and the results were compared. Significant differences were observed in catastrophizing and fear, which has also been reported in Western countries ${ }^{20)}$. Interestingly, each of the psychological aspects were negative in the intractable group, which implies that poor psychological condition has a negative effect on WAD treatment. Similarly, a previous study in a Western country found that chronic whiplash syndrome is triggered by emotional discomfort and psychological distress ${ }^{21}$. In addition, individuals with somatization often complain of pain in various locations, functional disturbance of various organ systems, and are depressed or overwhelmed by these symptoms. Therefore, patients in this situation are thought to suffer from functional somatic syndrome ${ }^{21)}$, and their psychological factors likely affect their treatment for WAD. In the present study, the mean EQ-5D score for the intractable group was 0.674, which was similar to the previously reported score for chronic widespread pain $(\mathrm{CWP})^{22)}$. Thus, patients with WAD and chronic widespread pain experience a marked decrease in their $\mathrm{QOL}^{23,24)}$.

This study has several limitations. Due to its cross-sectional design, we cannot comment on the causality of the relation- 
ship between psychological factors and WAD treatment. In addition, our participants were internet research volunteers, who may not accurately represent the general population. For example, our participants were more likely to live in large cities compared to the general population. In addition, our respondents were more likely to have university-level or graduate-level education $^{25)}$. However, the effect of any potential selection bias on our results would be difficult to elucidate. Despite these limitations, this study could provide useful insights to orthopedic surgeons who are tasked with treating patients with WAD.

In conclusion, poor psychological condition was associated with prolonged treatment for WAD in Japanese adults. Therefore, psychological factors should be considered during the treatment of WAD.

\section{REFERENCES}

1) Yayama T, Kokubo Y, Uchida K, et al.: Pathophysiology of the traumatic cervical spine syndrome. Seikei Geka, 2012, 63: 797-801 (in Japanese).

2) Cassidy JD, Carroll LJ, Côté P, et al.: Effect of eliminating compensation for pain and suffering on the outcome of insurance claims for whiplash injury. $\mathrm{N}$ Engl J Med, 2000, 342: 1179-1186. [Medline] [CrossRef]

3) Kamper SJ, Rebbeck TJ, Maher CG, et al.: Course and prognostic factors of whiplash: a systematic review and meta-analysis. Pain, 2008, 138: 617-629. [Medline] [CrossRef]

4) Sterling M: Does knowledge of predictors of recovery and nonrecovery assist outcomes after whiplash injury? Spine, 2011, 36: S257-S262. [Medline] [CrossRef]

5) Carroll LJ, Cassidy JD, Côté P: The role of pain coping strategies in prognosis after whiplash injury: passive coping predicts slowed recovery. Pain, 2006, 124 : 18-26. [Medline] [CrossRef]

6) Myrtveit SM, Wilhelmsen I, Petrie KJ, et al.: What characterizes individuals developing chronic whiplash?: the Nord-Trøndelag Health Study (HUNT). J Psychosom Res, 2013, 74: 393-400. [Medline] [CrossRef]

7) Oka H, Matsudaira K, Fujii T, et al.: Risk factors for prolonged treatment of whiplash-associated disorders. PLoS One, 2015, 10: e0132191. [Medline] [CrossRef]

8) Miller RP, Kori SH, Todd DD: The Tampa Scale: a measure of kinisophobia. Clin J Pain, 1991, 7: 51-52. [CrossRef]

9) Matsudira K, Ishizuka K, Kikuchi N, et al.: Development of a Japanese Version of the Tampa Scale for Kinesiophobia (TSK-J): Translation and Linguistic Validation. Rinsho Seikei Geka, 2013, 48: 13-19 (in Japanese).

10) Sullivan MJ, Pivik J: The pain catastrophizing scale: development and validation. Psychol Assess, 1995, 7: 524-532. [CrossRef]

11) Matsuoka H, Sakano Y: Assessment of cognitive aspect of pain: development, reliability, and version of pain catastrophizing scale. J Psychosom Med, 2007, 47: $95-102$.

12) Ware JE Jr, Sherbourne CD: The MOS 36-item short-form health survey (SF-36). I. Conceptual framework and item selection. Med Care, 1992, 30: 473-483. [Medline] [CrossRef]

13) Yamazaki S, Fukuhara S, Green J: Usefulness of five-item and three-item Mental Health Inventories to screen for depressive symptoms in the general population of Japan. Health Qual Life Outcomes, 2005, 3: 48. [Medline] [CrossRef]

14) Derogatis LR, Melisaratos N: The Brief Symptom Inventory: an introductory report. Psychol Med, 1983, 13: 595-605. [Medline] [CrossRef]

15) Matsudaira K, Inuzuka K, Kikuchi N, et al.: Development of the Japanese version of the brief symptom inventory-somatization scale; translation and linguistic validation. Orthop Surg, 2012, 63: 149-153 (in Japanese).

16) Matsudaira K, Palmer KT, Reading I, et al.: Prevalence and correlates of regional pain and associated disability in Japanese workers. Occup Environ Med, 2011, 68: 191-196. [Medline] [CrossRef]

17) Dolan P: Modeling valuations for EuroQol health states. Med Care, 1997, 35: 1095-1108. [Medline] [CrossRef]

18) Japanese EuroQol Translation Team: The development of the Japanese EuroQol instrument. J Health Care Soc, 1997, 8: 109-123 (in Japanese).

19) Japanese Official Statistics, Ministry of Internal Affairs and Communications: Population Census 2010. http://www.e-stat.go.jp/SG1/estat/List. do?bid=000001034991\&cycode $=0$ (Accessed Sep. 4, 2014) (in Japanese)

20) Walton DM, Macdermid JC, Giorgianni AA, et al.: Risk factors for persistent problems following acute whiplash injury: update of a systematic review and meta-analysis. J Orthop Sports Phys Ther, 2013, 43: 31-43. [Medline] [CrossRef]

21) Henningsen P, Zipfel S, Herzog W: Management of functional somatic syndromes. Lancet, 2007, 369: 946-955. [Medline] [CrossRef]

22) Yamada K, Matsudaira K, Takeshita K, et al.: Prevalence of low back pain as the primary pain site and factors associated with low health-related quality of life in a large Japanese population: a pain-associated cross-sectional epidemiological survey. Mod Rheumatol, 2014, 24: 343-348. [Medline] [CrossRef]

23) Clauw DJ, Crofford LJ: Chronic widespread pain and fibromyalgia: what we know, and what we need to know. Best Pract Res Clin Rheumatol, 2003, 17: 685-701. [Medline] [CrossRef]

24) Mourão AF, Blyth FM, Branco JC: Generalised musculoskeletal pain syndromes. Best Pract Res Clin Rheumatol, 2010, 24: 829-840. [Medline] [CrossRef]

25) Japanese Official Statistics, Ministry of Internal Affairs and Communications: Population Census and Labour Force Survey 2007. http://www.stat.go.jp/data/ index.htm (Accessed Sep. 4, 2014) (in Japanese) 